\title{
Effective Psychological Treatment of Adult Male Sexual Offenders
}

\author{
William L. Marshall ${ }^{1}$
}

[1] Rockwood Psychological Services, Midland, Canada.

Sexual Offending: Theory, Research, and Prevention, 2021, Vol. 16, Article e7473, https://doi.org/10.5964/sotrap.7473

Received: 2021-03-16 • Accepted: 2021-04-26 • Published (VoR): 2021-11-10

Handling Editor: Martin Rettenberger, Centre for Criminology (Kriminologische Zentralstelle - KrimZ), Wiesbaden, Germany

Corresponding Author: William L. Marshall, PO Box 50, Inverary, Ontario, Canada, K0H1X0. Phone: 613-353-6281. E-mail: bill@rockwoodpsyc.com

\begin{abstract}
This paper describes psychological approaches to the treatment of sexual offenders. The empirically generated principles of effective treatment are outlined followed by the identification of the evidence-based issues that need to be addressed. The established important role of the therapists' behaviors during treatment is then described along with the effectiveness of recruitment strategies and of tactics aimed at ensuring all entrants complete the program. Metaanalytic reports describing treatment efficacy are considered followed by an outline of the appraisal of the effectiveness of two large scale independent treatment programs. Finally, a brief description of a cost-benefit report indicates that when treatment of sexual offenders effectively reduces re-offense rates, it also saves a considerable amount of taxpayers' money.
\end{abstract}

\section{Keywords}

treatment, sexual offenders, sexual offenses, sexual abuse, crime prevention, effectiveness

\section{Non-Technical Summary}

\section{Background}

The present article summarizes the scientific knowledge about treatment programs for individuals convicted of sexual offenders, which are using psychological approaches instead of, for example, medications or other kinds of treatments. 


\section{Why was this review done?}

There is a long discussion in the field of forensic psychology and psychotherapy if psychological treatment for individuals convicted of sexual offenses is effective or not. The present review will give a clear answer to this question.

\section{What did the researcher find?}

Today we know that psychological treatment is effective, if certain aspects are followed: First, it is important that persons who have a higher risk for committing further crimes should receive more treatment. Second, it is important to focus on the most relevant and important treatment aims. Third, it is necessary to use treatment techniques, which fit the language and social styles of the clients. Further important aspects of effective psychological treatment approaches include the considerations of strengths and resources (not only deficits and problems) and to ensure that no client cancel his participation in the treatment program before it is officially over.

\section{What do these findings mean?}

If the above-mentioned and further issues are appropriately considered, we are able to reduce the risk of offending behavior and of further victims.

\section{Highlights}

- When following the basic principles of risk, need, and responsivity (RNR) we know that psychological treatment of sexual offenders significantly reduces relapse rates.

- Furthermore, empirical studies indicated that when treatment reduces reoffending, it is also cost-effective.

- The first step of successful treatment programs is the strive for the participating of as many clients as possible and the reduction of rates of retention after the entry into treatment programs.

- A cornerstone of effective treatment programs is the addressing of so-called criminogenic needs, which have to fulfill the following essential characteristics: It has to be empirically related to recidivism in sexual offenders and is has to be potentially modifiable.

Modern psychologically-based treatment programs for sexual offenders were initially implemented in the late 1960s and early 1970s (Laws \& Marshall, 2003; Marshall \& Laws, 2003). Initially the most common approach involved the application of some form of behavior therapy derived from Pavlovian conditioning (e.g., Bond \& Evans, 1967). Beginning in the 1970s, programs became more comprehensive by incorporating various "cognitive/behavioral" strategies and by targeting an increasingly broader range of issues. Many of the targets addressed in these early approaches were later found to not 
be relevant to effective treatment (Thornton \& D’Orazio, 2017) and were, or should have been, eliminated from therapy with these clients. Nevertheless, variations on Cognitive Behavioral Therapy (CBT) came to be the entrenched approach adopted by the majority of programs for these offenders.

There is now a considerable body of literature on CBT programs as applied to these clients (Marshall \& Marshall, 2017a). Since the number of published reports is too extensive to be fully covered here, the focus will be limited to the most relevant issues that are supported by solid bodies of evidence. While this paper will be restricted to the treatment of adult male sexual offenders, many of the issues and evidence addressed are, within limits, relevant to the treatment of women and juvenile offenders. More specific information on the treatment of female offenders has been reported by Cortoni (2017), and Worling and Langton (2017) have described programs for juveniles.

\section{Principles of Effective Treatment}

In a report that laid the foundations of all offender rehabilitation programs, Andrews et al. (1990) described an empirically-derived set of principles to guide treatment. The embodiment of these guides is referred to as the Risk/Needs/Responsivity (RNR) principles. These principles were later shown by Hanson, Bourgon, Helmus, and Hodgson (2009) to also apply to the treatment of sexual offenders. The Risk Principle indicates that treatment resources should be invested according to the empirically determined risk level of the clients with most resources given to the highest risk offenders. Where sufficient funds are available, somewhat less extensive treatment should be allocated to moderate risk offenders with fewer, if any, given to the treatment of low risk offenders. A reasonable justification for not investing resources in this latter group of men, is that treatment appears unlikely to further reduce their risk. The Needs Principle demands that treatment focus upon, and be limited to, addressing those deficits that have been shown to both predict a propensity to reoffend and be, at least potentially, modifiable. These features are typically described as "criminogenic needs".

The Responsivity Principle refers to the requirement that treatment be delivered in a therapeutic style that is consistent with a wide-ranging body of evidence. This body of evidence is derived both from the general psychotherapeutic literature (e.g., Norcross, 2002) and from the evidence evinced within the cognitive/behavioral treatment of various psychological disorders (Schaap, Bennun, Schindler, \& Hoogduin, 1993). More directly relevant evidence for the value of applying this principle comes from studies reported by Marshall et al. $(2002,2003)$. They showed that in the treatment of sexual offenders, the presence of four features displayed by the therapists explained between $40 \%$ and $60 \%$ of the changes produced by treatment. Perhaps not surprisingly, when therapists were judged to be empathic, warm, and encouraging, all the goals of treatment were achieved. Helpful guidance offered by the therapists, when necessary, also contributed to 
the attainment of the goals of treatment. However, when therapists were judged to be confrontational, or aggressively challenging, any gains that might otherwise have been derived, vanished. Beech and Hamilton-Giachritsis (2005) also reported that a harsh challenging approach eliminated any positive changes that might otherwise have resulted from sexual offender treatment. Finally, on these issues, it has been found that when all three of Andrews' principles are appropriately applied within the treatment of adult sexual offenders, the long-term reductions in reoffending are significant (Olver, 2017).

Despite the empirically-based observations described above, many sexual offender programs fail to conform to the RNR-principles. These programs characteristically do not address all criminogenic factors, nor do they provide treatment resources proportional to each offender's risk level. For instance, survey data (McGrath, Cumming, \& Burchard, 2003; McGrath, Cumming, Burchard, Zeoli, \& Ellerby, 2010) has revealed that very few United States programs appropriately adhere to these established principles of effective treatment. Instead, many of the details of these programs cling to outmoded models of treatment and target numerous issues that have no criminogenic status in terms of the evidence. Indeed, many of the treatment targets of these US programs, have been shown to not be predictors of a propensity to reoffend. Thus, valuable treatment time is wasted in these programs by targeting non-relevant issues which results in a failure to be able to appropriately address the truly criminogenic problems. Reinforcing these observations, Gannon, Olver, Mallion, and James (2019) found that such programs characteristically failed to produce reductions in reoffending. Fortunately, this comprehensive meta-analysis did reveal that some treatment approaches produced reductions in reoffending. These effective programs were characterized by the following features: a) they adhered to Andrews et al's principles of treatment allocation and delivery; b) they addressed only criminogenic factors; and c) they employed therapists who had a minimum of a Master's degree in psychology. The authors also noted that programs in Canada, Australia, and New Zealand were among those consistently producing benefits (Gannon et al., 2019).

What then is it that characterizes these effective programs? As we have seen, to reduce reoffending, treatment must adhere to the RNR-principles. Aside from the allocation of resources primarily to the treatment of high risk clients, treatment must be directed at the issues that have been shown to both predict reoffending and be potentially changeable. These issues are referred to as "criminogenic factors".

\section{Appropriate Targets of Treatment}

Before addressing the targets of treatment that have sound empirical bases, it needs to be noted that the way treatment is introduced to newly entering clients is quite important. Therapists in many programs claim, without any basis in evidence, that it is necessary to begin treatment by having clients describe their offense(s) and admit to all the details contained in police and victim reports; these latter reports are assumed to be veridical. 
The descriptions clients offer of their offenses are then challenged, often in an aggressive manner, because it is believed that these accounts express self-protective views and will, thereby, impede progress in treatment. There is, however, no evidence that securing clients' full admission to the details of their offense is essential to subsequent treatment engagement or to their disposition to reoffend (Marshall \& Marshall, 2017b). Indeed, Maruna and Mann (2006) showed that among all types of offenders, those who readily admitted to having committed a crime, and were quite willing to describe the details, were more likely to reoffend than were offenders who displayed defensiveness and denial. The same has been shown with non-offending people who have done, or said, something offensive to others (Marshall, Marshall, \& Kingston, 2011; Marshall, Marshall, \& Ware, 2009).

Contrary to these entrenched ideas, initial treatment engagement is most effectively secured by dealing with clients in a supportive and respectful manner (Prescott \& Wilson, 2013). Additionally, rather than focusing early in treatment on clients' deficits, as is so often the approach, it is more motivational to assist them in identifying the strengths they have displayed in the past, and that currently characterize them. Indeed, such "strength-focused" approaches to treatment have been shown to be effective with these clients (Marshall \& Marshall, in press). Once the confidence of clients is secured, treatment can progress to addressing the truly "criminogenic factors".

The empirical bases for identifying the appropriate criminogenic targets have been summarized by Hanson and his colleagues (Hanson, Harris, Scott, \& Helmus, 2007; Hanson \& Harris, 2000; Mann, Hanson, \& Thornton, 2010). To qualify as a criminogenic target, two essential characteristics must be met: 1) each issue must have been shown to predict reoffending; and 2) each problem must be potentially modifiable. On this latter point, some aspects of these clients that have been shown to predict reoffending, reflect static (i.e., unchangeable) characteristics. For example, an offender under age 25-years is at greater risk to reoffend than is true for older clients. Similarly, an offender with an extensive history of having committed other types of offenses is more likely to be identified as a reoffender (see Rettenberger \& Craig, 2017, for more details).

Mann et al. (2010) also specified the so-called "dynamic" (i.e., potentially changeable) features of sexual offenders. Included in this empirically-derived list were: difficulties in establishing effective adult romantic relationships (Rich, 2017); poor behavioral self-regulation (Stinson, Becker, \& Sales, 2008); inadequate control over sexual behavior, often described as "sexual addiction" or "sexual compulsivity" (Marshall \& Marshall, 2006); evidence of sexual deviance derived from measures of sexual responses to appropriate and deviant sexual stimuli (Wilson, 2017); and an array of so-called "distorted cognitions" (Ó Ciardha \& Gannon, 2011). These latter distortions include, but are not restricted to, a belief that children desire sex with an adult, or that women enjoy being raped.

As noted earlier, despite clear evidence that each of the dynamic features, and only these features, predict a propensity to reoffend, and should, therefore, be the sole targets 
of interventions, many programs not only fail to address each of these issues but also target an array of empirically unjustified aspects of these clients. The question then arises is "do programs that follow the above-mentioned principles reduce reoffending?" However, before examining the evidence on long-term reductions in reoffending resulting from appropriate treatment, there are two additional features relevant to the confidence we can assign to outcome reports; namely, how many of the available offenders enter treatment and how many who engage in treatment actually complete all aspects of the program.

\section{Client Recruitment and Retention}

It seems obvious that when sexual offender programs are unable to accommodate all available offenders, and to also retain all recruited clients throughout treatment, limits should be placed on the relevance of their outcome evaluations. When treatment providers carefully select only those clients who are deemed to be at low risk, then the re-offense rates generated by such programs will have limited meaning. Indeed, any selection process that deliberately restricts entry to treatment for some clients automatically limits any generalizations that might otherwise be justified. Similarly, if the rate of dropouts during treatment is high, the relevance of any apparent benefits will be questionable. Unfortunately, evidence on these important issues is limited.

Some researchers (e.g., Browne, Foreman, \& Middleton, 1998; Brunner et al., 2019; Mann, Webster, Wakeling, \& Keylock, 2013; Seager, Jellicoe, \& Dhaliwal, 2004) have reported rates of acceptance of an offer of treatment and rates of retention after entry into treatment. The acceptance rates outlined in these studies, range from $13 \%$ to $52 \%$, while other reports noted completion rates as low as 14\% (Shaw, Herkov, \& Greer, 1995) and as high as $64 \%$ (Lee et al., 1996). A meta-analysis of attrition rates in sexual offender treatment programs analyzed 114 studies representing a total of 41,438 offenders and showed a $27.6 \%$ mean rate of attrition (Olver et al., 2011). These are not impressive data. Marshall, Marshall, Serran, and O’Brien (2011) also described acceptance and retention data for their prison-based program. In this comprehensive description of their program, they reported offering a place in their program to all sexual offenders (i.e., 100\%) who entered the prison where treatment was provided. Of those offered treatment, $96.2 \%$ accepted the offer and entered the program. Of those who entered treatment, $95.8 \%$ completed all aspects of the program. To date these are the most positive data reported in the literature on these important issues. The above-mentioned issues are important not only in considering the value of a program, but also in the confidence we may assign to any outcome data. The following, then, describes reports of such outcome data. 


\section{Outcome Evaluations}

In evaluations of the benefits of treatment for sexual offenders, researchers have relied on criminal justice data on reoffending. The comprehensive nature of these data is, however, not always certain. For example, in the United States offenders released from prison may move to other states making tracking difficult and in many cases impossible. The same could eventually be true for Europe where movement across borders is fluid. Canada, fortunately, has a nation-wide data base (CPIC) held by the Royal Canadian Mounted Police. It is important to note that all police and prosecutors across the country must keep this data base up-to-date by entering all convictions for all crimes.

Despite the noted limitations on data from some countries, several meta-analyses of the outcome of sexual offender treatment (Gannon et al., 2019; Hanson et al., 2002; Lösel \& Schmucker, 2005; Schmucker \& Lösel, 2015) have reported significantly lower rates for treated clients (12\% to $14 \%$ ) than for untreated offenders (13\% to $17 \%)$. More specifically, long-term outcome assessments of programs operated by psychologists directly employed by Correctional Service of Canada (CSC) have revealed significant results. These programs (Looman, Abracen, \& Nicholaichuk, 2000; Nicholaichuk, Gordon, Gu, \& Wong, 2000; Nicholaichuk, Olver, Gu, \& Wong, 2014) reported lower rates of reoffending among the treated men (12\%) than among the untreated clients $(17 \%)$.

In addition, a more recent long-term (11.5 years follow-up) evaluation of two CSC prison-based treatment approaches (Olver, Marshall, Marshall, \& Nicholaichuk, 2020) found that both programs generated lower rates of reoffending than was evident in a comparison group of untreated clients. Reoffending rates, derived from CPIC's data base, were generated in order to compare the outcome from CSC's standard program (SOTP, $n=625$ ), with the effects of an independently contracted program based in a CSC prison (hereafter described as "Rockwood", $n=579$ ). The re-offense rates of both these programs were compared with each other and with a group of untreated offenders $(n=107)$. Each treatment group generated lower re-offense rates (SOTP $=12.6 \%$; Rockwood $=5.4 \%$ ) over the follow-up period than was true for the untreated men (19.6\%). Comparisons of these outcome data revealed significant differences between each of the three groups. It is worth noting that the SOTP data are consistent with the findings of the various meta-analyses reported earlier while the benefits derived from Rockwood's program are clearly much higher.

There is, however, one recent outcome evaluation that reported what appears to be an anomalous re-offense rate among untreated offenders. Mews, Di Bella, and Purver (2017) examined the outcome of treatment provided within Her Majesty's Prison Service (HMPS). They reported that the re-offense rate for offenders treated within HMPS prisons was $10 \%$, whereas among the group they identified as "untreated" the rate was $8 \%$. Note that the treated rate is well within (indeed at the lower end of) the re-offense range reported in the meta-analyses. It is the re-offense rate of the untreated clients that appears to be anomalous. Closer examination of this study reveals that the authors did 
not take into account the distinct possibility that the purportedly "untreated" men may have received further treatment from the Probation Services once the men were released from prison. The focus of this study was restricted to the treatment provided within the prisons. To clarify the relevance of this concern, it is noted that HMPS has jurisdiction over both prisons and the probation services, and it requires probation units to provide, where possible, treatment upon release from prison. Thus, it is possible, indeed likely, that the so-called "untreated" men did, in fact, receive treatment. It is of course not possible to determine this account but it would certainly explain the anomalously low offense rate (8\%) among the "untreated" men. Overall, then, with this study being an exception, the reports of treatment outcome reveal positive benefits from treatment. But does this provide sufficient justification for the expenses associated with the provision of treatment?

As a result of the positive findings concerning Rockwood's prison-based treatment, Marshall and Marshall (2021) examined the potential financial benefits produced by the reductions in reoffending generated by this program. They found considerable financial savings to the criminal justice system for this particular provision of treatment. Estimates, derived in terms of reduced expenses to the criminal justice system (i.e., police investigations, prosecutors' preparations, court expenses) as a result of lower re-offense rates, revealed that Rockwood's program saved the Canadian taxpayers in excess of \$14 million dollars during the years of its operation that were evaluated in the outcome study (i.e., between 1991 and 2001). Thus, when treatment is effective it not only saves many women and children from harm, it also appears to be a sound financial investment by funding agencies (usually the government).

\section{Conclusions}

This paper has outlined the format and content of treatment for sexual offenders that is necessary to secure beneficial outcomes. It was shown that treatment can only be expected to be effective if empirically established principles are followed. When treatment programs adhere to these guidelines, they appear to generate significant reductions in re-offense rates thereby saving countless women and children from suffering at the hands of these men. These results should be sufficient to persuade funding agencies that their money is well spent. This position is bolstered by evidence showing that when treatment reduces reoffending, it is also cost-effective.

Funding: The author has no funding to report.

Acknowledgments: The author has no additional (i.e., non-financial) support to report.

Competing Interests: The author has declared that no competing interests exist. 


\section{References}

Andrews, D. A., Zinger, I., Hoge, R. D., Bonta, J., Gendreau, P., \& Cullen, F. T. (1990). Does correctional treatment work? A clinically relevant and psychologically informed meta-analysis. Criminology, 28, 369-404. https://doi.org/10.1111/j.1745-9125.1990.tb01330.x

Beech, A. R., \& Hamilton-Giachritsis, C. E. (2005). Relationship between therapeutic climate and treatment outcome in group-based sexual offender treatment. Sexual Abuse: A fournal of Research and Treatment, 17, 127-140. https://doi.org/10.1177/107906320501700204

Bond, I. K., \& Evans, D. R. (1967). Avoidance therapy: Its use in two cases of underwear fetishism. Canadian Medical Association fournal, 96, 1160-1162.

Browne, K. D., Foreman, L., \& Middleton, D. (1998). Predicting treatment dropout in sex offenders. Child Abuse Review, 7, 402-419. https://doi.org/10.1002/(SICI)1099-0852(199811/12)7:6<402::AID-CAR530>3.0.CO;2-9

Brunner, F., Neumann, I., Yoon, D., Rettenberger, M., \& Briken, P. (2019). Determinants of dropout from correctional offender treatment. Frontiers in Psychiatry, 10, Article 142. https://doi.org/10.3389/fpsyt.2019.00142

Cortoni, F. (2017). Treatment of female sex offenders. In L. E. Marshall \& W. L. Marshall (Eds.), The Wiley handbook on the theories, assessments, and treatment of sexual offending (Vol. 3: Treatment, pp. 1265-1283). Chichester, United Kingdom: John Wiley \& Sons.

Gannon, T. A., Olver, M. E., Mallion, J. S., \& James, M. (2019). Does specialized psychological treatment for offending reduce recidivism? A meta-analysis examing staff and program variables as predictors of treatment effectiveness. Clinical Psychology Review, 73, Article 101752. https://doi.org/10.1016/j.cpr.2019.101752

Hanson, R. K., Bourgon, G., Helmus, L., \& Hodgson, S. (2009). The principles of effective correctional treatment also apply to sexual offenders: A meta-analysis. Criminal fustice and Behavior, 36, 865-891. https://doi.org/10.1177/0093854809338545

Hanson, R. K., Gordon, A., Harris, A. J. R., Marques, J. K., Murphy, W. D., Quinsey, V. L., \& Seto, M. C. (2002). First report of the Collaborative Outcome Data Project on the effectiveness of psychological treatment of sex offenders. Sexual Abuse: A Journal of Research and Treatment, 14, 169-194. https://doi.org/10.1177/107906320201400207

Hanson, R. K., \& Harris, A. J. R. (2000). Where should we intervene? Dynamic predictors of sex offender recidivism. Criminal fustice and Behavior, 27, 6-35. https://doi.org/10.1177/0093854800027001002

Hanson, R. K., Harris, A. J. R., Scott, T.-L., \& Helmus, L. M. (2007). Assessing the risk of sexual offenders on community supervision (User Report No. 2007-05). Ottawa, Ontario, Canada: Public Safety and Emergency Preparedness Canada.

Laws, D. R., \& Marshall, W. L. (2003). A brief history of behavioral and cognitive behavioral approaches to sexual offenders: Part 1. Early developments. Sexual Abuse: A fournal of Research and Treatment, 15, 75-92. https://doi.org/10.1177/107906320301500201 
Lee, J. K. P., Proeve, M. J., Lancaster, M., \& Jackson, H. J. (1996). An evaluation and 1-year follow-up of a community-based treatment program for sex offenders. Australian Psychologist, 31, 147-152. https://doi.org/10.1080/00050069608260196

Looman, J., Abracen, J., \& Nicholaichuk, T. P. (2000). Recidivism among treated sexual offenders and matched controls: Data from the Regional Treatment Centre (Ontario). Fournal of Interpersonal Violence, 15, 279-290. https://doi.org/10.1177/088626000015003004

Lösel, F., \& Schmucker, M. (2005). The effectiveness of treatment for sexual offenders: A comprehensive meta-analysis. fournal of Experimental Criminology, 1, 117-146. https://doi.org/10.1007/s11292-004-6466-7

Mann, R. E., Hanson, R. K., \& Thornton, D. (2010). Assessing risk for sexual recidivism: Some proposals on the nature of psychologically meaningful risk factors. Sexual Abuse: A fournal of Research and Treatment, 22, 191-217. https://doi.org/10.1177/1079063210366039

Mann, R. E., Webster, S. D., Wakeling, H. C., \& Keylock, H. (2013). Why do sexual offenders refuse treatment? Journal of Sexual Aggression, 19, 191-206. https://doi.org/10.1080/13552600.2012.703701

Marshall, L. E., \& Marshall, W. L. (2006). Sexual addiction in incarcerated sexual offenders. Sexual Addiction \& Compulsivity, 13, 377-390. https://doi.org/10.1080/10720160601011281

Marshall, L. E., \& Marshall, W. L. (Eds.). (2017a). The Wiley handbook of theories, assessment, and treatment of sexual offending (Vol. 3: Treatment). Chichester, United Kingdom: John Wiley \& Sons.

Marshall, L. E., \& Marshall, W. L. (2017b). Motivating sex offenders to enter and effectively engage in treatment. In D. Wilcox, R. Gray, R. Donathy, \& B. Brim (Eds.), Working with sex offenders: A guide for practitioners (pp. 98-112). Oxford, United Kingdom: Routledge.

Marshall, W. L., \& Laws, D. R. (2003). A brief history of behavioral and cognitive behavioral approaches to sexual offender treatment: Part 2. The modern era. Sexual Abuse: A fournal of Research and Treatment, 15, 93-120. https://doi.org/10.1177/107906320301500202

Marshall, W. L., \& Marshall, L. E. (2021). A cost-benefit analysis of a treatment program for adult males who have offended sexually. Journal of Sexual Aggression. Advance online publication. https://doi.org/10.1080/13552600.2021.1934133

Marshall, W. L., \& Marshall, L. E. (in press). Strength-based treatments for adults and juveniles who have been sexually abusive: A review. In C. M. Langton \& J. R. Worling (Eds.), The Wiley handbook of offender desistence from aggression and crime: Theory, research and evidence-based practice. Chichester, United Kingdom: John Wiley \& Sons.

Marshall, W. L., Marshall, L. E., \& Kingston, D. A. (2011). Are cognitive distortions of child molesters in need of treatment? Journal of Sexual Aggression, 17, 118-129. https://doi.org/10.1080/13552600.2011.580572

Marshall, W. L., Marshall, L. E., Serran, G. A., \& O’Brien, M. D. (2011) Rehabilitating sexual offenders: A strength-based approach. Washington, DC, USA: American Psychological Association. 
Marshall, W. L., Marshall, L. E., \& Ware, J. (2009). Cognitive distortions in sexual offenders: Should they all be treatment targets? Sexual Abuse in Australia and New Zealand, 2, 70-78.

Marshall, W. L., Serran, G. A., Fernandez, Y. M., Mulloy, R. E., Mann, R. E., \& Thornton, D. (2003). Therapist characteristics in the treatment of sexual offenders: Tentative data on their relationship with indices of behavior change. Journal of Sexual Aggression, 9, 25-30. https://doi.org/10.1080/355260031000137940

Marshall, W. L., Serran, G. A., Moulden, H., Mulloy, R., Fernandez, Y. M., Mann, R. E., \& Thornton, D. (2002). Therapist features in sexual offender treatment: Their reliable identification and influence on behavior change. Clinical Psychology \& Psychotherapy, 9, 395-405. https://doi.org/10.1002/cpp.335

Maruna, S., \& Mann, R. E. (2006). A fundamental attribution error? Rethinking cognitive distortions. Legal and Criminological Psychology, 11(2), 155-177. https://doi.org/10.1348/135532506X114608

McGrath, R. J., Cumming, G. F., \& Burchard, B. L. (2003). Current practices and trends in sexual offender management: Safer Society 2002 nation wide survey. Brandon, VT, USA: Safer Society Press.

McGrath, R. J., Cumming, G. F., Burchard, B. L., Zeoli, S., \& Ellerby, L. (2010). Current practices and emerging trends in sexual abuser management. Brandon, VT, USA: Safer Society Press.

Mews, A., Di Bella, L., \& Purver, M. (2017). Impact evaluation of the prison-based Core Sex Offender Programme (Minister of Justice Analytical Series). Retrieved from https://assets.publishing.service.gov.uk/government/uploads/system/uploads/attachment_data/ file/623876/sotp-report-web-.pdf

Nicholaichuk, T., Gordon, A., Gu, D., \& Wong, S. (2000). Outcome of an institutional sexual offender program: A comparison between treated and matched untreated offenders. Sexual Abuse: A fournal of Research and Treatment, 12, 139-153. https://doi.org/10.1177/107906320001200205

Nicholaichuk, T. P., Olver, M. E., Gu, D., \& Wong, S. C. P. (2014). Age, actuarial risk, and long-term recidivism in a national sample of sex offenders. Sexual Abuse: A fournal of Research and Treatment, 26, 406-428. https://doi.org/10.1177/1079063213492340

Norcross, J. C. (2002). Empirically supported therapy relationships. In J. C. Norcross (Ed.), Psychotherapy relationships that work: Therapist contributions and responsiveness to patient needs (pp. 3-10). New York, NY, USA: Oxford University Press.

Ó Ciardha, C., \& Gannon, T. A. (2011). The cognitive distortions of child molesters are in need of treatment. Fournal of Sexual Aggression, 17, 130-141.

https://doi.org/10.1080/13552600.2011.580573

Olver, M. E. (2017). The Risk-Need-Responsivity Model: Applications to sex offender treatment. In L. E. Marshall \& W. L. Marshall (Eds.), The Wiley handbook on the theories, assessment, and treatment of sexual offending (Vol. 3: Treatment, pp. 1313-1329). Chichester, United Kingdom: John Wiley \& Sons. 
Olver, M. E., Marshall, L. E., Marshall, W. L., \& Nicholaichuk, T. P. (2020). A long-term outcome assessment of the effects on subsequent re-offense rates of a prison-based CBT/RNR sex offender treatment program with strength-based elements. Sexual Abuse: A fournal of Research and Treatment, 32(2), 127-153. https://doi.org/10.1177/1079063218807486

Olver, M. E., Stockdale, K. C., \& Wormith, J. S. (2011). A meta-analysis of predictors of offender treatment attrition and its relationship to recidivism. Journal of Consulting and Clinical Psychology, 79(1), 6-21. https://doi.org/10.1037/a0022200

Prescott, D. P., \& Wilson, R. J. (2013). Awakening motivation for difficult changes. Holyoke, MA, USA: Safer Society Press.

Rettenberger, M., \& Craig, L. A. (2017). Actuarial risk assessment of sexual offenders. In L. A. Craig $\&$ M. Rettenberger (Eds.), The Wiley handbook on the theories, assessments, and treatment of sexual offending (Vol. 2: Assessment, pp. 609-641). Chichester, United Kingdom: John Wiley \& Sons.

Rich, P. (2017). The ties that bind: Relationship and attachment targets in work with sex offenders. In L. E. Marshall \& W. L. Marshall (Eds.), The Wiley handbook on the theories, assessments, and treatment of sexual offending (Vol. 3: Treatment, pp. 1403-1420). Chichester, United Kingdom: John Wiley \& Sons.

Schaap, C., Bennun, I., Schindler, L., \& Hoogduin, K. (1993). The therapeutic relationship in behavioural psychotherapy. Chichester, United Kingdom: John Wiley \& Sons.

Schmucker, M., \& Lösel, F. (2015). The effects of sexual offender treatment on recidivism: An international meta-analysis of sound quality evaluations. Fournal of Experimental Criminology, 11, 597-630. https://doi.org/10.1007/s11292-015-9241-z

Seager, J. A., Jellicoe, D., \& Dhaliwal, G. K. (2004). Refusers, dropouts, and completers: Measuring sex offender treatment efficacy. International fournal of Offender Therapy and Comparative Criminology, 48, 600-612. https://doi.org/10.1177/0306624X04263885

Shaw, T. A., Herkov, J. M., \& Greer, R. A. (1995). Examination of treatment completion and predicted outcome among incarcerated sex offenders. The Bulletin of the American Academy of Psychiatry and the Law, 23, 35-41.

Stinson, J. D., Becker, J. V., \& Sales, B. D. (2008). Self-regulation and the etiology of sexual deviance: Evaluating causal theory. Violence and Victims, 23, 35-52.

https://doi.org/10.1891/0886-6708.23.1.35

Thornton, D., \& D’Orazio, D. M. (2017). Advancing the evolution of sexual offender risk assessment: The relevance of psychological risk factors. In L. E. Craig \& M. Rettenberger (Eds.), The Wiley handbook on the theories, assessments, and treatment of sexual offending (Vol 2: Assessment, pp. 667-693). Chichester, United Kingdom: John Wiley \& Sons.

Wilson, R. J. (2017). The use of phallometric testing in the diagnosis, treatment, and risk management of male adults who have sexually offended. In L. A. Craig \& M. Rettenberger (Eds.), The Wiley handbook on the theories, assessment, and treatment of sexual offending (Vol. 2: Assessment, pp. 823-848). Chichester, United Kingdom: John Wiley \& Sons. 
Worling, J. R., \& Langton, C. M. (2017). Treatment of adolescents who have sexually offended. In L. E. Marshall \& W. L. Marshall (Eds.), The Wiley handbook on the theories, assessments, and treatment of sexual offending (Vol. 3: Treatment, pp. 1245-1263). Chichester, United Kingdom: John Wiley \& Sons.

IATSO=-

International Association for the
Ireatment of Sexucl Offenders

Sexual Offending: Theory, Research, and Prevention (SOTRAP) is the official journal of the International Association for the Treatment of Sexual Offenders (IATSO).
(P) leibniz-psychology.org

PsychOpen GOLD is a publishing service by Leibniz Institute for Psychology (ZPID), Germany. 